\title{
Thermal Study of Solar Parabolic Concentrator
}

\author{
Karima Ghazouani, Safa Skouri, Salwa Bouadila, Amenallah Guizani \\ The Research and Technology Center of Energy, the Thermal Processes Laboratory, Hammam Lif, B.P. 95, \\ 2050 Tunis, Tunisia
}

\begin{abstract}
The advancement in parabolic dish technologies has led to the development of steam generation; a feasible and efficient solution that utilizes the sun's energy for heat supply in industrial processes as well as for thermal power generation. In this paper a solar parabolic dish with aperture area of 3.8 was designed, manufactured and evaluated is presented. In order to improve the thermal efficiency, reduce the heat losses and achieve steam production of the concentrator solar power (CSP), many experimental tests were carried out in the Research and Technology Center of Energy (CRTEn) in Tunisia. $2 \mathrm{~m}$
\end{abstract}

Keywords - Oil, Parabolic dish, Steam generation, Thermal efficiency, Water.

\section{Introduction}

In the last ten years, oil prices became very high as well as the reserves amounts have been decreased. Moreover, burning fossil fuels such as coal, oil and natural gas for energy generation causes global warming and pollution problems. Based upon these facts, new resources of clean energy are necessarily needed. Renewable energy is the promising solution to this problem. Therefore, significant researches have been reported on how to utilize renewable energy resources efficiently. One of the most important resources of renewable energy is the solar energy which has widely spreading applications. It has been used for water heating, direct electricity generation by means of photovoltaic, and for steam generation. It is estimated that earth receives approximately $1000 \mathrm{~W} / \mathrm{m} 2$ amount of solar irradiation in a day [1].The CSP (concentrated solar power) is considered as the most prominent solar energy technology. There are four types of CSP technologies: parabolic trough, linear Fresnel, solar tower and solar dish [2,3]. In 1901, Eneas in Pasadena, California operated a solar steam engine which was powered by a reflective dish [4]. In the late 1970, Omnium [5] designed a parabolic dish collector system that would run a steam engine. It was constructed from panels of polyurethane foam with a reflecting anodized surface. Thomas [6] reviewed various aspect of solar steam generation using solar concentrator.

The model proposed by Folaranmi [7] was steam generator from a parabolic dish concentrator. Using this collector, heat from the sun is concentrated on a black absorber which is placed on the focal point of the dish concentrator. Water is heated at very high temperature to form steam. The model arrangement is mounted on a hinged frame supported with a slotted lever for tilting the parabolic dish reflector to different angles. This will make the sun always directed towards the collector at different period of the day. The test results from this model shows temperature above $200{ }^{\circ} \mathrm{C}$ on average sunny and cloud free day. N.D Kaushika and K.S Reddy [8] present the design and performance characteristics of a low cost solar steam generating system which incorporates recent design of parabolic dish technology. Preliminary field measurements and cost, as well as performance analyses of the system, indicate a solar to steam conversion efficiency of $70 \pm 80 \%$ at $4508 \mathrm{C}$ and a collector system cost of Rs $8000 \pm 9000 / \mathrm{m} 2$ (US $\$ 1=\mathrm{Rs}, 40.0$ ).

The Australian National University has worked for many years on paraboloidal dish solar concentrators and demonstrated a $400 \mathrm{~m} 2$ system in 1994. K.Lovegrove et al.[9] demonstrated a $500 \mathrm{~m} 2$ concentrator with $13.4 \mathrm{~m}$ focal length and altitude-azimuth tracking. It uses 380 identical spherical $1.17 \mathrm{~m} \times 1.17 \mathrm{~m}$ mirror panels, which incorporate the Glass-on-Metal Laminate mirrors. The first on sun test was carried out on 29 June 2009. Vishal R. Sardeshpande et al.[10] proposed a test procedure for characterization of point-focus steam generating solar concentrators based on latent heating at different operating temperatures. This procedure can be used to estimate thermal efficiency of solar concentrator at different operating temperatures above $100{ }^{\circ} \mathrm{C}$. Fareed.M.Mohamed et al.[11] designed and fabricated a solar dish concentration with diameters (1.6) meters for water heating application and solar steam. In this experiment, Water temperature increased up to $80^{\circ} \mathrm{C}$, and the system efficiency increased by $30 \%$ at mid noon time. 


\section{Experimental Setup}

Our experimental setup is a solar parabolic dish designed and constructed in (CRTEn). The experimental system of the solar parabolic concentrator SPC is mainly composed of a parabola provided with an absorber placed by three arms at the focal position. A reflector embedded in a nacelle rotatable around two axes: the horizontal axis (elevation angle) from the support supported by a mast and the second is the vertical axis (azimuth angle) and counterbalancing. The characteristics of the SPC are given in Table 1.

Table 1: Parameters of reflector

\begin{tabular}{|l|c|c|}
\hline Geometrical parameters & Value & Unit \\
\hline Opening diameter of the parabola $D_{0}$ & 2.2 & $\mathrm{~m}$ \\
\hline Aperture area of the parabola S & 3.8 & $\mathrm{~m}^{2}$ \\
\hline Depth of the parabola $\mathrm{m}$ & 0.4 & $\mathrm{~m}$ \\
\hline Focal distance f & 0.75 & $\mathrm{~m}$ \\
\hline Mass of the dish M & 49.8 & $\mathrm{Kg}$ \\
\hline Position of the center of inertia $G_{p}$ & 0.26 & $\mathrm{~m}$ \\
\hline
\end{tabular}

The equation for the parabola in cylindrical coordinates is defined as:

$$
Z=\frac{r^{2}}{4 f}
$$

The focal distance $\mathrm{f}$ is given by the following expression:

$$
f=\frac{d^{2}}{16 h}
$$

The paraboloid surface $\mathrm{S}$ with opening diameter $\mathrm{d}$ is given by:

$$
S=\frac{8 \pi}{3} f^{2}\left\{\left[1+\left(\frac{r}{2 f}\right)^{2}\right]^{3 / 2}-1\right\}
$$

The opening surface of a paraboloid $\mathrm{S}_{0}$ is given by:

$$
S_{0}=\frac{\pi d^{2}}{4}
$$

Using concentrating collector, heat from the sun is concentrated on a black absorber located at the focus point of the reflector in which oil is heated to a very high temperature. It also describes the sun tracking system unit by manual tilting of the lever at the base of the parabolic dish to capture solar energy. The whole arrangement is mounted on a hinged frame supported with a slotted lever for tilting the parabolic dish reflector to different angles so that the sun is always directed to the collector at different period of the day (Fig 1).

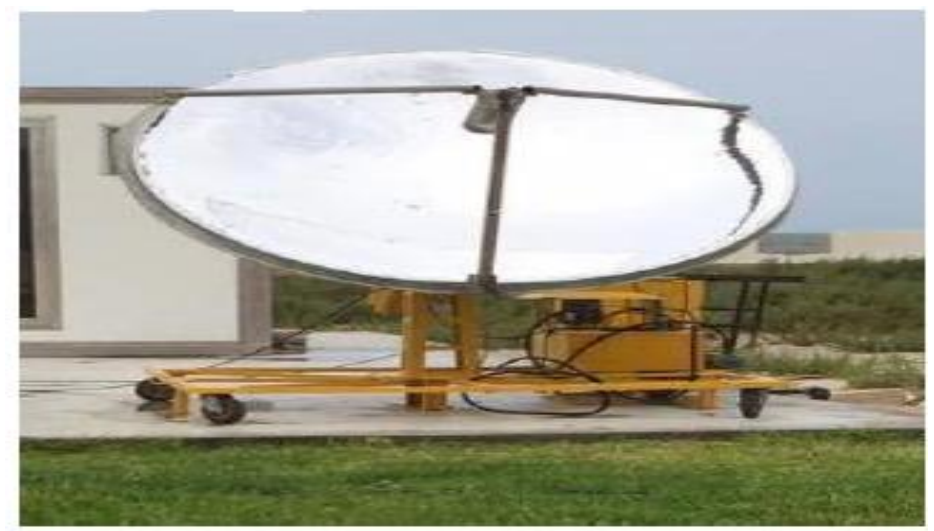

Figure 1: Installation of parabolic solar collector. 
In this experiment, we used 6 Thermocouples (Type $\mathrm{K}$, precision $\pm 0.5^{\circ} \mathrm{C}$ ) in order to determine the ambient temperature, inlet and outlet oil temperature, inlet and outlet water temperature, the temperature in the interior of water reservoir and a pyranometer CM 11 used to determine global radiation during this experiment. We used acquisition system of data CR5000 in order to control and verify the quality of established data.

\subsection{Study of Solar Radiation}

\section{Results and Discussion}

\subsubsection{Estimated Direct and Diffuse Radiation}

The estimation of global solar radiation is essential for utilization the solar energy, design wherever appropriate observations missing [12]. The measurement of global and diffuse radiations at ground was performed by a pyranometer. The Solar radiation who reaches the ground is formed by a direct radiation and a diffuse radiation which they are together form the global radiation [13] and [14], we dedicate these respectful radiation respectively by the letters $I$ (direct), $D$ (diffuse) et $G$ (global), all these are calculated with $\mathrm{W}$ m- 2 .

The diffuse radiation $\mathrm{D}$, the direct radiation $\mathrm{I}$ and the global radiation $\mathrm{G}$ obtained by simple integration:

$$
\begin{aligned}
& I=E \tau_{b} \cos (h) \\
& D=E \tau_{d} \cos (h) \\
& G=I+D
\end{aligned}
$$

$\mathrm{E}$ is the solar constant; $\mathrm{h}$ is the elevation angle, $\tau_{b}$ is the transparency of the atmosphere for direct radiation and $\tau_{d}$ is the transparency of the atmosphere for diffuse radiation.

The transparency of the atmosphere for direct radiation $\tau_{b}$ determined by the formula presented by Hottel (1976).

$$
\begin{aligned}
& \tau_{b}=r_{0} a_{0}+r_{1} a_{1} \exp \left(-r_{k} k / \sin (h)\right) \\
& a_{0}, a_{1}, \mathrm{k} \text { coefficients depending of } \mathrm{Z} . \\
& a_{0}=0.4237-0.00821(6-z)^{2} \\
& a_{1}=0.50550 .00595 \mathrm{~m}^{2}(6.5-z)^{2} \\
& \mathrm{~K}=0.2711+0.01858(2.5-z)^{2} \\
& \text { In our case } \mathrm{Z}=0 \\
& r_{0}, r_{1}, r_{k} \text { coefficients depending of climate. }
\end{aligned}
$$

The transparency of the atmosphere for diffuse radiation $\tau_{d}$ determined by the following expression:

$$
\tau_{d}=0.2710-0.2939 \tau_{b}
$$

\subsubsection{Experimental Study of Solar Radiation}

Figures 2 and 3 present climatic conditions during the experiment which illustrate the temporal variation of global and direct solar radiation of parabolic dish and ambient temperature. We note that much of the global solar radiation is absorbed by the absorber placed in the foyer. We also observe that the direct energy increases with sunshine. For a maximum value of global energy $800 \mathrm{~W}$ at noon, direct solar radiation is $200 \mathrm{~W}$ for ambient temperature equal to $30^{\circ} \mathrm{C}$.

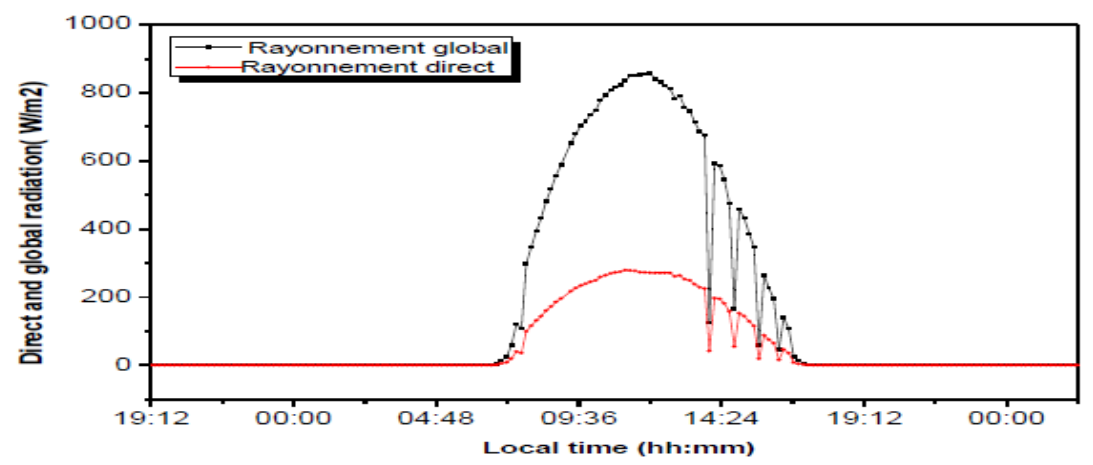

Figure 2: Temporal variation in the global and direct solar radiation. 


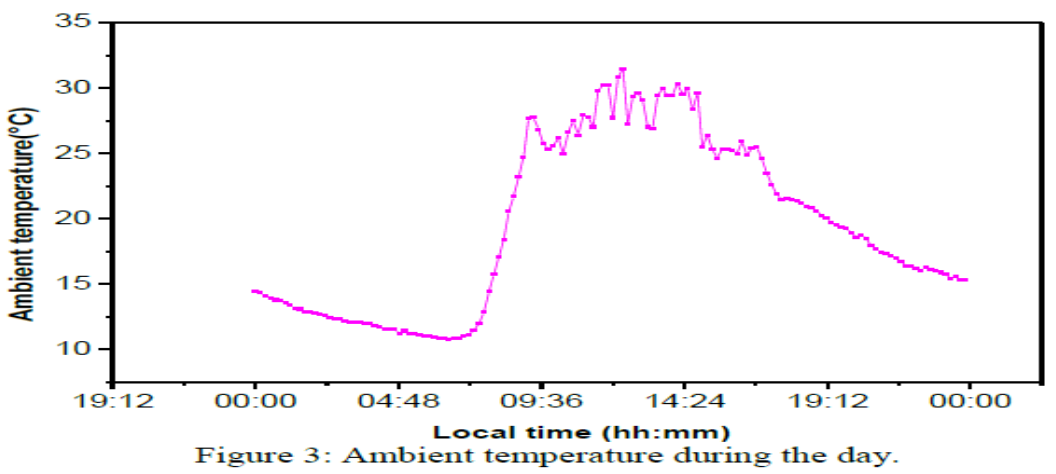

\subsection{Study of the Variation of Oil Temperature}

In this experience, we study the variation of the oil temperature in input and output as a function of local time (Fig 4). At the beginning of the day, we notice a small difference of temperature of the order of $5{ }^{\circ} \mathrm{C}$ then it increases rapidly and it becomes of the order of $30^{\circ} \mathrm{C}$. At the beginning of the day, the outlet temperature of oil of the order of $50{ }^{\circ} \mathrm{C}$ then it increases after $9 \mathrm{~h} 30$ until a maximum value $80{ }^{\circ} \mathrm{C}(\mathrm{Fig} 4)$.

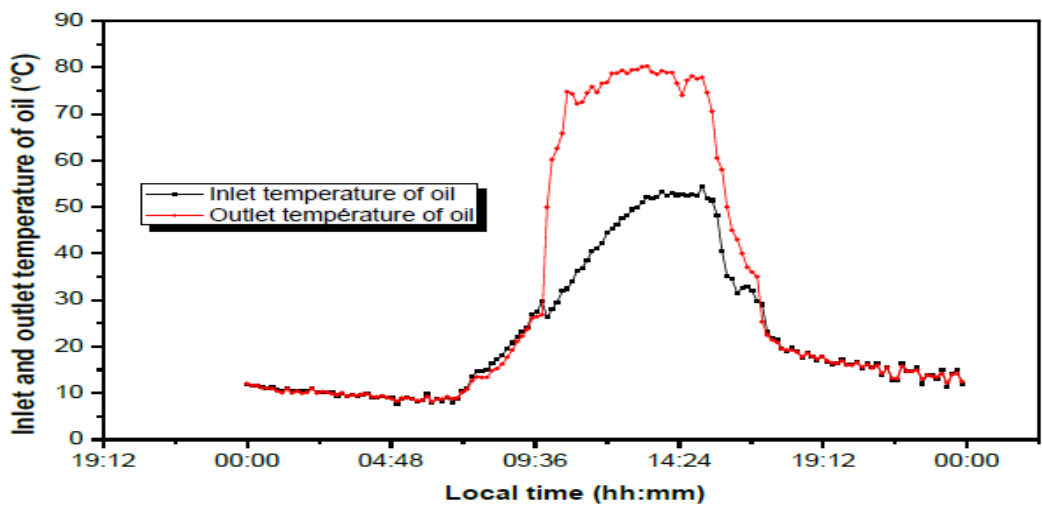

Figure 4: the variation of the oil temperature in input and output as a function of local time.

The heat flux u Q extracted by the absorber is expressed by the following expression [15]:

$$
Q_{u}=\dot{m} C_{p}\left(T_{\text {outlet }}-T_{\text {inlet }}\right)
$$

Using this equation, we obtained Figure 5 which presents the variation of the useful power of the oil as a function of local time. We can say that the useful power of oil is proportional to the temperature difference in inlet and outlet. The optimum value of the experimental useful energy varied between $10 \mathrm{~W} / \mathrm{m}^{2}$ and $30 \mathrm{~W} / \mathrm{m}^{2}$, for maximum radiation equal to $800 \mathrm{~W} / \mathrm{m}^{2}$. Experimental fluctuations due to the precision of tracking system (Fig $5)$.

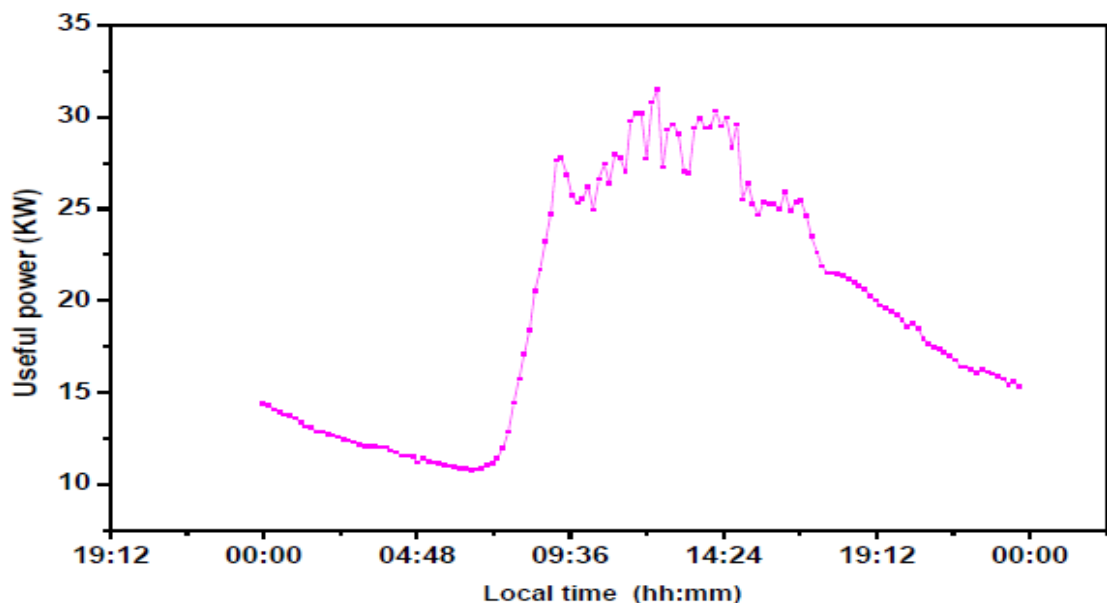

Figure 5: The variation of the useful power of the oil as a function of local time. 
The thermal efficiency of the SPC is given by the following expression [15]:

$$
\begin{gathered}
\eta_{e n}=\frac{Q_{u}}{I} \\
C_{R}=\frac{A_{a} Q_{u}}{A_{a b} I}
\end{gathered}
$$

We carried out an analysis of energy efficiency of CSP. Figure 6 present the variation of experimental thermal efficiency and the concentration ratio as a function of local time. Therefore it is found that the thermal efficiency of CSP during the day varied between $40 \%$ to $77 \%$ and it represent a concentration ratio of the order of 150 .

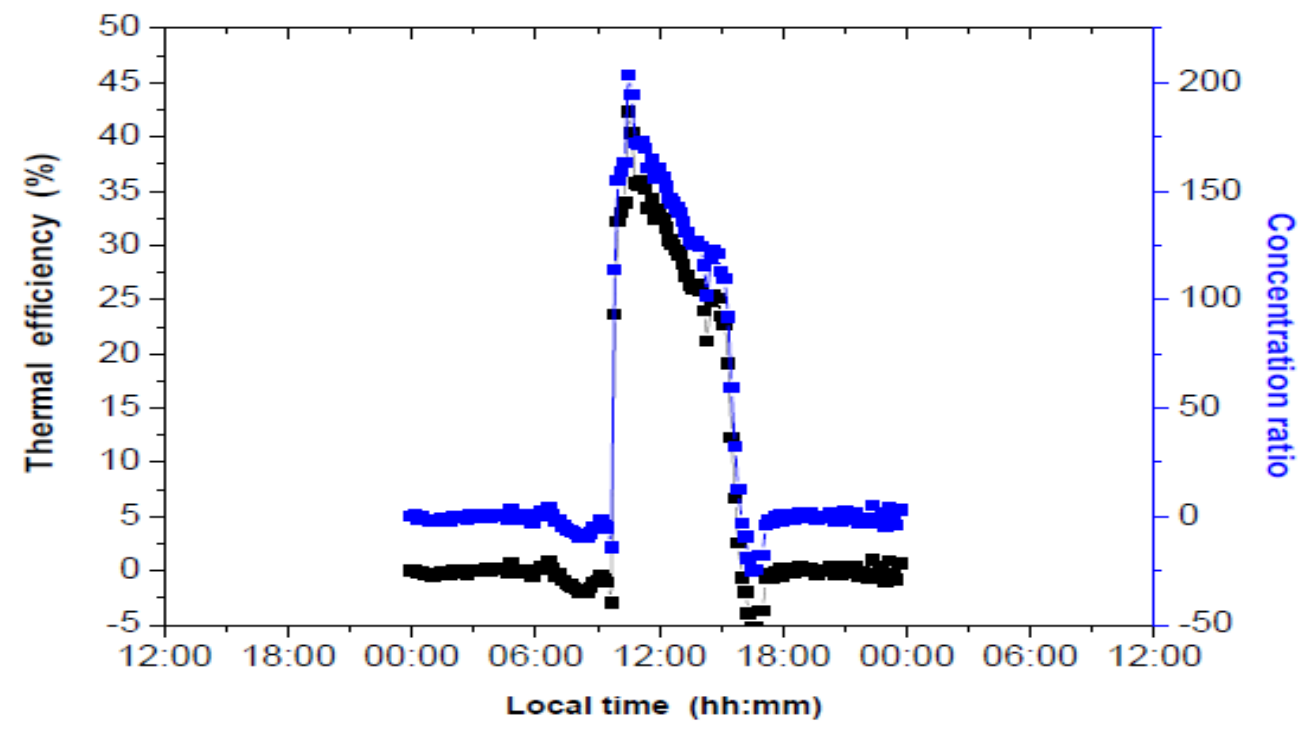

Figure 6: The variation of experimental thermal efficiency and the concentration ratio as a function of local time.

\subsection{Study of the Variation of Water Temperature}

Figure 7 shows temporal variation of the inlet and outlet temperature of water and temperature of water reservoir. Also according to the experimental study, it follows that we can achieve an outlet temperature of $85^{\circ} \mathrm{C}$ for a very high flow which shows that it may have an outlet temperature much more important for low flow and we can have other applications by the device such as steam generation.

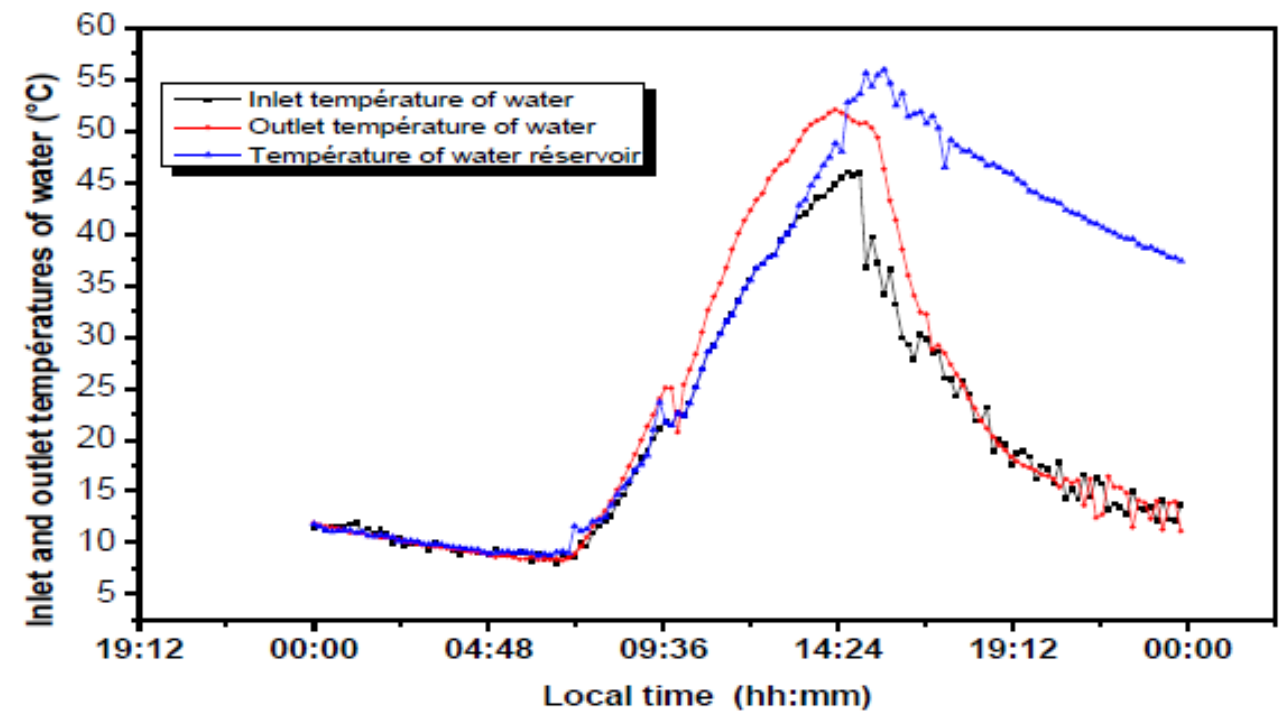

Figure 7: Temporal variation of the inlet and outlet temperature of water and temperature of water reservoir

International Conference on Recent Innovations in Civil \& Mechanical Engineering $\quad 122 \mid$ Page [i-CAM2K16] DOI: 10.9790/1684-1605304118123 


\section{Conclusion}

This work is a contribution of a solar parabolic concentrator equipped with a manual tracking. Using this collector, heat from the sun is concentrated on a black absorber which is placed on the focal point of dish concentrator. Water is heated at very high temperature to form steam. In this experiment, we find that for a maximum value of global energy $800 \mathrm{~W}$ at noon, direct solar radiation is $200 \mathrm{~W}$, for ambient temperature equal to $30^{\circ} \mathrm{C}$. We find also that the outlet temperature of oil of the order of $50{ }^{\circ} \mathrm{C}$ at the beginning of the day then it increases after $9 \mathrm{~h} 30$ until a maximum value $80{ }^{\circ} \mathrm{C}$. The average concentration ratio and average energy efficiency are respectively around 150 and between $40 \%$ to $77 \%$. This device can be used for different applications like pasteurization and detoxication.

\section{References}

[1]. R. Winston, J.C. Minano, P. Benitez, Nonimaging Optics, Elsevier Academic Press, 2005.

[2]. Lob_on DH, Valenzuela L. Impact of pressure losses in small-sized parabolictrough collectors for direct steam generation. Energy 2013;61:502e12

[3]. Zhong Y, Roman MB, Zhong Y, Archer S, Chen R, Deitz L, et al. Using anaerobic digestion of organic wastes to biochemically store solar thermal energy. Energy 2015;83:638e46.

[4]. El-Refaie MF. Concentrated solar thermal power. Renew Energy Energy Efficiency MENA Region 2009

[5]. El-Refaie MF. Concentrated solar thermal power. Renew Energy Energy Efficiency MENA Region 2009.)

[6]. Thomas A. Solar steam generating systems using parabolic trough concentrators. Energy Convers Manage 1996;37:215-45.)

[7]. Folaranmi J. Design, construction and testing of a parabolic solar steam generator. Leonardo Electronic Journal of Practices and Technologies 2009;(14):115-33.)

[8]. N.D KAUSHIKA, K.S REDDY. PERFORMANCE OF A LOW COST SOLAR PARABOLOID DISH STEAM GENERATING SYSTEM. ENERGY CONVERSION AND MANAGEMENT 2000; 7:713-726.

[9]. K. Lovegrove, , G. Burgess, J. Pye. A new $500 \mathrm{~m} 2$ paraboloidal dish solar concentrator. Solar Energy 2011; 4: 620626. Paper title (11italic)

[10]. Vishal R. Sardeshpande, Ajay G. Chandak, Indu R. Pillai. Procedure for thermal performance evaluation of steam generating point-focus solar concentrators Solar Energy (2011); 85: 1390-1398.

[11]. Fareed. M. Mohamed, Auatf.S.Jassim, Yaseen. H. Mahmood, Mohamad A.K.Ahmed, "Design and Study of Portable Solar Dish Concentrator”, International Journal of Recent Research and Review, Vol. III, September 2012.

[12]. Iqbal, M., 1983. An Introduction to Solar Radiation. Academic Press, Canada, pp. 91-94.

[13]. Bernard, J., 2011. Energie Solaire: Calculs et Optimisation, Technosup, Ge'nie e'nerge'tique. Ellipsis Marketing, Paris, 383p.

[14]. Bernard, R., Menguy, G., Schwartz, M., 1980. Le Rayonnement Solaire: Conversion Thermique et Application, Technique et Documentation, Paris, 215p

[15]. Bertrand, A., 1980. Exploitation Des Nouvelles Capacite's D’observation De La Terre Pour Evaluer Le Rayonnement Solaire Incident Au Sol, The`se de Doctorat, ED N 432: “Science des Me'tiers de l'Inge'nieur", e'cole nationale supérieure des mines de Paris.

[16]. Chassériaux JM. Conversion thermique du rayonnement solaire. France: Agence Française pour la maîtrise de l'énergie; 1979. 